\title{
Measuring retention in care for HIV-positive pregnant women in Prevention of Mother-to-Child Transmission of HIV (PMTCT) option B+ programmes: the Mozambique experience
}

\author{
Laurence Ahoua ( $\square$ laurence_ahoua@yahoo.fr) \\ Universite de Bordeaux https://orcid.org/0000-0002-6565-502X \\ Thierry Tiendrebeogo \\ Universite de Bordeaux
}

Shino Arikawa

Universite de Bordeaux

Maria Laheurta

Columbia University

Dario Aly

ICAP Mozambique

Renaud Becquest

Universite de Bordeaux

Francois Dabis

Universite de Bordeaux

Research article

Keywords: PMTCT, option B+, retention, sensitivity, specificity

Posted Date: November 27th, 2019

DOI: https://doi.org/10.21203/rs.2.12007/v2

License: (c) (1) This work is licensed under a Creative Commons Attribution 4.0 International License.

Read Full License

Version of Record: A version of this preprint was published at BMC Public Health on March 12th, 2020. See the published version at https://doi.org/10.1186/s12889-020-8406-5. 


\section{Abstract}

Background: Failure of retention of HIV-positive pregnant women on ART leads to increased mortality for the mother and her child. This study evaluated different retention measures intended to measure women's engagement along the continuum of care for PMTCT option B+ services in Mozambique. Methods: We compared 'point' retention (patient's presence in care at 12-months post-ART initiation or any time thereafter) to the following definitions: alive and in care at 12 months post-ART initiation (Ministry of Health); attendance at a health facility up to 15 months post-ART initiation (World Health Organisation); alive and in treatment at 1, 2, 3, 6, 9, and 12 months post-ART initiation (Inter-Agency Task Team); and alive and in care at 12 months post-ART initiation with $\geq 75 \%$ appointment adherence during follow-up (i.e. 'appointment adherence' retention) or with $\geq 75 \%$ appointment done on-time during follow-up (i.e. 'ontime adherence' retention). Kaplan-Meier survival curves were produced to assess variability in retention rates. We used 'on-time adherence' retention as our reference to estimate sensitivity, specificity, and proportion of misclassified patients. Results: Considering the 'point' retention definition, 16,840 HIVpositive pregnant women enrolled in option B+ PMTCT services were identified as 'retained in care' 12 months post-ART initiation. Of these, $60.3 \%$ (95\% Cl 59.6-61.1), 84.8\% (95\% Cl 84.2-85.3), and $16.4 \%$ (95\% $\mathrm{Cl} 15.8-17.0)$ were classified as 'retained in care' using $\mathrm{MOH}, \mathrm{WHO}$, and IATT definitions, respectively, and $1.2 \%(95 \% \mathrm{Cl} 1.0-1.4)$ were classified as 'retained in care' using the ' $\geq 75 \%$ on-time adherence' definition. All definitions provided specificity rates of $\geq 98 \%$. The sensitivity rates were $3.0 \%$ with $78 \%$ of patients misclassified according to the WHO definition and $4.3 \%$ with $54 \%$ of patients misclassified according to the $\mathrm{MOH}$ definition. The 'point' retention definition misclassified $97.6 \%$ of patients. Using IATT and 'appointment adherence' retention definitions, sensitivity rates $(9.0 \%$ and $11.7 \%$, respectively) were also low; however, the proportion of misclassified patients was smaller $(15.9 \%$ and $18.3 \%$, respectively). Conclusion: More stringent definitions indicated lower retention rates for PMTCT programmes. Policy makers and programme managers should include attendance at follow-up visits when measuring retention in care to better guide planning, scaling up, and monitoring of interventions.

\section{Background}

In 2015, WHO recommended that all HIV-positive pregnant women be provided with lifelong antiretroviral therapy (ART) regardless of their CD4 count and WHO staging, also called "Option B+" (1). Compared to previous prevention of mother-to-child transmission (PMTCT) of HIV regimen such as Option A (short term anti-retroviral prophylaxis) or Option B (triple anti-retroviral until end of breastfeeding) (2), Option B+ by providing the same antiretroviral triple-combination to all HIV-positive pregnant women for life has the advantage of lowering the risk of HIV transmission to male partners since being on ART will make women less infectious, reducing the risk of MTCT of HIV in subsequent pregnancies while reducing the risk of child infection to less than $5 \%$ in resources limited settings (3).

Retention in PMTCT care has both individual and public health implications. For mother-infant pair, being in care contributes to higher maternal ART adherence, better viral suppression, and ensures better postnatal care, including full ART prophylaxis and complete infant testing for HIV-exposed infants $(\mathrm{HEI})(4,5)$. 
In contrast, failure to be retained in care can lead to delayed or inconsistent use of antiretroviral medications, higher risk of maternal viral load failure, and increased morbidity and mortality for the mother and her child (6-8). In addition, recent publications have reported an upward trend in acquired drug resistance to first-line ART across low- and middle-income countries, principally due to sub-optimal viral suppression (9-11). Therefore, non-achievement of viral suppression can lead to a higher risk of HIV transmission and secondary infections with acquired drug resistance strains and is, therefore, considered a public health threat (12).

When referring to retention in care, publications often consider 'point' retention, which is defined in relation to a patient's presence in care at a certain time point (13). For women and children enrolled in PMTCT services, attendance at a clinic at a certain time point is often considered to be full retention over this time period. While such a simple definition is useful, it has been demonstrated that between one- and two-thirds of HIV-infected adult patients are not in regular care (14). Therefore, regularity of attendance is an important parameter to consider if the quality of engagement in care is to be evaluated (15).

To address shortcomings in this simple definition, attempts have been made to better measure retention in care in PMTCT services $(16,17)$. In 2014, a World Health Organisation (WHO) monitoring and evaluation working group published consolidated strategic information guidelines and proposed that retention in care of HIV-infected pregnant and breastfeeding women was equivalent to attendance at a health facility at 12-months post-initiation of ART, or at any time up to 3 months later (16). The 12-month time point was agreed to align with the adult ART monitoring guidelines; however, it fails to address HIV transmission risk beyond 12 months due to prolonged breastfeeding. In 2015, the Inter-Agency Task Team (IATT) on Children and HIV and AIDS defined maternal retention as 'the proportion of HIV-positive pregnant and/or breastfeeding women on ART alive and in treatment at 1, 2, and 3 months post-ART initiation (early retention), and then at 6, 9, and 12 months post-ART initiation', where retention was considered as a continuous engagement (17). Despite such efforts, there is no consensus on what constitutes 'retention in care', and no gold standard has been determined to date. In 2010, Mugavero et al. provided a synopsis of five commonly used definitions of retention in HIV care and treatment services, ranging from a simple count of the number of missed visits to a more complex medical visit performance measure that incorporated elements of appointment consistency and gaps in care (14). While that study provided important insights on methodological and conceptual strengths and limitations of each definition, no comparative analysis of these definitions has been undertaken. We hypothesised that 'point' retention' might overestimate the level of engagement in care of women enrolled in PMTCT programmes giving a false image of clinical and programmatic success. In a high HIV-burden country such as Mozambique, women's engagement should be more precisely assessed in order to identify windows of opportunity for possible improvement throughout the PMTCT care continuum and to better account for the number of children in need of ART (18).

In this study, we aimed to answer the following questions: what is the effect of different definitions of retention in care on the interpretation of women's engagement along the PMTCT continuum of care programmes under Option B+ in Mozambique? What are the advantages and limitations of each 
definitions? Finally, what other measures of retention besides 'point retention' that could reflect more accurately the nature of women's engagement along the PMTCT care continuum? Specifically, the study: i) assessed the variability of different measures of retention at 12 months post-ART initiation under PMTCT option B+ programmes using six different definitions of retention in care; (ii) compared the sensitivity and specificity of the different definitions in detecting women fully engaged in care at 12 months post-ART initiation; and (iii) discussed the programmatic implications of each definition in the context of PMTCT option B+ programmes.

\section{Methods}

\section{Study design}

This was a retrospective cohort study involving secondary analysis of routinely collected data.

\section{Setting}

Data were extracted from all sites with available electronic patient-level databases (ePLD), representing a total of 86 Ministry of Health $(\mathrm{MOH})$ facilities in Nampula and Zambézia provinces in Mozambique which were included in the analysis. All of these sites provided PMTCT option B+ and HIV care and treatment services with the support of ICAP at Columbia University through funding from the United States President's Emergency Plan for AIDS Relief (PEPFAR).

Officially adopted in 2013, the option B+ strategy in Mozambique uses a 'one-stop-model' and 'Test and Treat' approach where pregnant and breastfeeding women are counselled and tested in mother and child health (MCH) services and, if found HIV-positive, are started on lifelong ART that same day. HIV care and treatment are integrated within $\mathrm{MCH}$ services and ART provision is administered by nurses. For HIVpositive pregnant women, a second consultation occurs within the first week post-ART initiation, and a monthly clinical follow-up is conducted during the first 6 months of ART, followed by bi-monthly followups during breastfeeding until 12 months of treatment and bi-annually thereafter until the end of breastfeeding. ART counselling and drug pickup are conducted on a monthly basis for the first year of treatment. Routine viral load (VL) monitoring is recommended at 3 and 12 months post-ART initiation and annually thereafter. HIV-positive women are followed in $\mathrm{MCH}$ services until the final HIV status of the exposed infant is determined (19). More detailed descriptions of the PMTCT programme settings and data sources are described elsewhere (20).

The Mozambique provinces targeted for the study officially implemented option B+ in July 2013. Of all HIV-positive women who were enrolled in PMTCT option B+ programmes and who were started on ART between July $1^{\text {st }}, 2013$ and December $31^{\text {st }}, 2017$, we selected those who were considered as 'retained in care' at 12 months post-ART initiation according to the 'point' retention definition (i.e. patient alive and present in care at 12 months post-ART initiation, or any time thereafter) and with a follow-up time of at least 12 months under ART to allow complete assessment of engagement in care during the first year of 
treatment. These selected women constituted the basis of comparison for the subsequent analyses assessing variability in different definitions concerning retention measures.

\section{Comparing definitions}

The 'point' retention definition was compared against the following five definitions: $\mathrm{MOH}$ (21), WHO (16), IATT (17), 'appointment adherence' retention (14), and 'on-time adherence' retention (22) (Table 1). Similar to the 'point' retention definitions, the $\mathrm{MOH}$ and $\mathrm{WHO}$ retention definitions assess retention at a single time point. For women's attendance at a clinic, we considered different types of visits including medical consultations, pharmacy drug refills, counselling, or laboratory analysis. This approach allowed us to consider HIV care as a holistic strategy, given that HIV care is provided in an increasingly team-based environment with non-prescribing healthcare professionals taking on expanded roles in direct patient care. Table 1 summarises the definitions of retention according to different measures and shows how failure events were accounted for in statistical analyses.

\section{Statistical analysis}

A total of 31,186 HIV-positive women enrolled in the PMTCT option B+ programme in $86 \mathrm{MOH}$ facilities in Nampula and Zambézia provinces and initiated ART during the study period. Women's appointment adherence, as well as their on-time adherence to scheduled visits, were expressed as percentages, median, and interquartile range [IQR]. Women's retention status was classified into a binary outcome (retained vs. not retained in care) using a 75\% threshold for clinical attendance. Each woman contributed to the analyses from the date of ART initiation to the first occurrence of a failure event, as described in Table 1. To allow sufficient time to analyse clinical attendance within the first year of treatment, we only included women who initiated ART up until December $31^{\text {st }}, 2016$ and for whom the theoretical follow-up time under ART was $\geq 12$ months.

Kaplan-Meier survival curves were produced to estimate retention in care at 3, 6, 9, and 12 months postART initiation using each of the definitions described above. We assessed variability in the different measures of retention between respective definitions used. We did not consider 'appointment adherence' retention for the survival analysis, as this definition does not contemplate a time event, but rather a total number of visits completed during the observation period.

We assessed sensitivity, specificity, and the proportion of misclassified women for each alternative definition of retention compared to the reference of an 'ideal case scenario' of full 'on-time adherence' retention, defined as a woman alive and in care 12 months post-ART initiation and ${ }^{3} 75 \%$ of scheduled visits attended on time (+/- 15 days). Sensitivity and specificity values were calculated with $95 \%$ confidence intervals.

\section{Results}


Of 31,186 HIV-positive women enrolled in the PMTCT option B+ programme during the study period, 18,739 were considered as being retained in care at 12 months post-ART initiation according to the 'point' retention definition. We excluded 1,899 women with a follow-up ART time of $<12$ months. Finally, 16,840 women were included in this study.

Of 16,840 women included, only 2,764 (16\%) and $407(2 \%)$ were considered retained at 12 months postART initiation when considering regularity and timeliness of appointment attendance, respectively (Figure 1). The occurrence of irregular (IATT's definition) and delayed ('on-time' definition) clinical attendance was documented as early as 2-3 months post-ART initiation. For all women included, the median appointment adherence was $66.7 \%$ (IQR $57.1 \%-80.0 \%$ ) and the median on-time adherence was $40.0 \%$ (IQR 22.2\% - 52.9\%) during the 12-month observation period.

Figure 2 shows Kaplan-Meier survival curves for retention over time up to 12-months post-ART initiation using the different definitions. Among the $16,840 \mathrm{~B}+$ pregnant women considered retained in care according to the 'point' retention definition, $84.8 \%$ (95\% Cl 84.2-85.3) were actually defined as retained in care when estimated using the WHO definition (i.e. attendance at a health facility up to 15 months postART initiation), $60.3 \%$ (95\% $\mathrm{Cl} 59.6-61.1$ ) with the $\mathrm{MOH}$ definition (i.e. alive and in care at 12 months post-ART initiation), and $16.4 \%(95 \% \mathrm{Cl} 15.8-17.0)$ with the IATT definition (i.e. alive and on treatment at $1,2,3,6,9$, and 12 months post-ART initiation), respectively. When using the 'on-time adherence' retention definition (i.e. alive and in care at 12 months post-ART initiation with at least $75 \%$ of on-time adherence during follow-up), only $1.2 \%(95 \% \mathrm{Cl} 1.0-1.4)$ were defined as retained in care.

We considered the reference category to be the 407 women alive and in care 12-months post-ART initiation with at least $75 \%$ on-time adherence. We calculated the sensitivity and specificity of other definitions to more accurately classify the women into a more suitable category of retention and determine the proportion of misclassified patients. While all definitions provided specificity rates of $\geq 98 \%$, the sensitivity to detect a patient actually retained in care with $\geq 75 \%$ of on-time adherence was $<12 \%$ (Table 2). The $\mathrm{WHO}$ and $\mathrm{MOH}$ retention definitions provided the lowest sensitivity figures and the highest proportion of women misclassified as retained in care as follows: $3.0 \%$ sensitivity $(95 \% \mathrm{Cl} 2.7 \%-$ $3.3 \%)$ with $78 \%$ of patients misclassified according to the WHO definition and $4.3 \%$ sensitivity $(95 \% \mathrm{Cl}$ $3.9 \%-4.7 \%$ ) with $54 \%$ of patients misclassified according to the $\mathrm{MOH}$ definition. In addition, the 'point' retention definition misclassified $97.6 \%$ of patients. Although sensitivity rates were also low when using the IATT and 'appointment adherence' retention definitions, the proportion of misclassified patients was relatively smaller (15.9\% and $18.3 \%$, respectively).

\section{Discussion}

We analysed six different definitions of 'retention in care' for HIV-positive pregnant women enrolled in PMTCT option B+ programmes ranging from the most lenient definition using a 'point' retention approach to the most stringent definition using an 'on-time adherence' retention approach. Of the six definitions, three definitions assess retention at a single time point ('point' retention, WHO, and MOH). The IATT, the 
'appointment' and the 'on-time adherence' retentions approaches reflect a more continuous engagement in care, where follow-up visits between initiation of ART and the endpoint date are considered.

As expected, we found that the more stringent the definition, the lower the probability for women to be defined as retained in care; and when levels of attendance to visits during follow-up were considered, estimates were even lower ( $85 \%$ and $60 \%$ when using the $\mathrm{WHO}$ and $\mathrm{MOH}$ definitions compared to $16 \%$ and $1 \%$ when using the IATT and 'on-time adherence' retention definitions). At the end of the first year, most women starting ART had not adhered to their scheduled visits, with median appointment adherence at $66 \%$ and median on-time adherence at $40 \%$ among the 16,840 women considered as retained in care using the 'point' retention definition. Of these, only $16 \%$ and $2 \%$ were actually defined as retained in care 12 months post-ART initiation, if we considered a threshold of $\geq 75 \%$ for appointment and on-time attendance, respectively.

Initial visits in the first year of ART initiation are critical to ensure successful engagement in care, involving intensive counselling, peer support, conveying important preventive healthcare and risk reduction messages, and monitoring patterns of healthier behaviour for the women and their exposed children. This interaction between the health system and the HIV-infected women determines the likelihood of survival of the pair and the mother-to-child transmission of HIV. Adding the frequency and regularity of visits into the concept of retention increases the quality of the PMTCT programme evaluations, enabling a distinction to be made between women who attend for all or some care and treatment, and those who completely fail to adhere to scheduled visits and are therefore considered not to be engaged in care.

Table 3 provides a summary of the advantages, limitations, and programmatic implications of the six measures of retention concerning the PMTCT option B+ programmes. Based on our results, the threesingle time point measures, namely, the 'point', $\mathrm{WHO}$, and $\mathrm{MOH}$ definitions, were a classical programmatic approach to measure retention in care under ART. While relatively easy to use, they do not capture important milestones in the PMTCT context; for example, at delivery, at 2-months post-partum for early infant diagnosis, or at the end of breastfeeding for the final HIV determination of the HIV-exposed infant. In addition, they do not consider visit consistency, which has been demonstrated to be significantly associated with ART adherence and viral suppression among HIV-positive adults $(23,24)$. However, the three definitions that capture visit consistency along the continuum of care, namely, the IATT, 'appointment' and 'on-time adherence' definitions, were more complex to use as they included multiple clinic visits (repeated measures) occurring longitudinally over time. This could become extremely challenging in limited-resource settings where limited qualified human resources are available to document such information, data collection tools are not adapted to capture longitudinal follow-up, and there are numerous entry points where women are followed within the same health facility or between sites $(15,25)$. To correctly capture patients' follow-up, different data sources need to be combined or triangulated, for example, with counselling registers and with laboratory or pharmacy records. Electronic databases may help this process, but these are generally implemented in high volume and accessible 
sites and may not necessarily be representative of the entire country for national programmes. However, all three definitions enabled adding the concept of a continuum of care to point retention estimates.

When considering 'on-time adherence' retention as the reference, all other definitions provided very low sensitivity rates to accurately detect patients retained in care, with high rates of misclassified patients. The $\mathrm{WHO}$ and $\mathrm{MOH}$ retention definitions provided the lowest sensitivity rates, that is, $3 \%$ and $4 \%$, respectively. For the 'point' retention, $\mathrm{WHO}$, and $\mathrm{MOH}$ definitions, which did not consider continuous follow-up in their calculations, the proportion of misclassified patients ranged from $54 \%$ to $97 \%$. The 'appointment adherence' definition provided the highest sensitivity rate (11.7\%), with a fairly low proportion of misclassified patients $(18.3 \%)$ compared to all other definitions analysed. We found that the median time to first failure of correct follow-up was short ( $\leq 3$ months), if visit attendance during followup was considered, which demonstrated the need to implement early preventive measures to avoid patients on the PMTCT programme disengaging from care. Such strategies should focus on already wellknown barriers to regular attendance, such as a lack of disclosure, poor staff attitudes, competing personal priorities, medication side-effects, or transport difficulties (22).

While our definition of 'on-time adherence' retention represents the ideal situation in which an HIV-positive pregnant woman enrols in a PMTCT programme and starts ART under option B+ should be considered as fully engaged in care to ensure an optimal viral response, it is perhaps too stringent for PMTCT programme evaluations. It is also time consuming to use on a routine basis and may not be compatible with current PMTCT service settings. Therefore, we recommend either using the IATT or the 'appointment adherence' retention definitions to better measure levels of engagement in care for mother-infant pairs.

Our analysis had several limitations. To accurately evaluate attendance at scheduled visits, it is desirable to distinguish visits cancelled in advance (either by the patient or the care provider) from 'no show' visits that are actually visits missed by the patient (14). Our data did not allow this distinction to be made as this information was not captured in the database. Therefore, our results may have underestimated the real values of women's engagement in care when analysing 'appointment' and 'on-time' adherence retentions.

Some women, although defined as having a full attendance at scheduled visits, did not follow per se the recommended schedule of visits as per national guidelines. More frequent visits may indicate a more advanced HIV disease, problems in counselling that need to be addressed, or drug or laboratory reagent stock-outs (25). Less frequent clinical visits may reflect a stabilised disease stage or temporary silent transfers (i.e. women receiving ART services elsewhere for a short period of time). For this reason, we chose to use all scheduled visits, regardless of whether the visits fell into expected time intervals. We did not analyse treatment interruptions and gaps in care for similar reasons. Further research is warranted to investigate the effect of a lack of observation of the recommended schedule of visits as per national guidelines on PMTCT programme outcomes.

Finally, we analysed data from health facilities with ePLD in two provinces in Mozambique. Although these two provinces are among the most populated in the country, with large volumes of patients seen at 
health facilities, our results may not be generalisable to other regions in Mozambique or to other resourcelimited settings.

\section{Conclusion}

Balancing the need to reflect correct attendance and capture the regularity of visits without involving complex computer processing of the available routine data can be a daunting task. In addition, applying more stringent definitions is likely to result in lower reported rates of retention in care for PMTCT programmes. However, policy makers and programme managers should consider systematically taking into account attendance at follow-up visits to better guide decision-making concerning planning or scaling up interventions for mother-infant pairs. A consensus on a practicable definition is urgently needed, based on data availability, clinic scheduling practices, and local analytical capacities. Without overall agreed guidelines, findings from different programmes and interventions cannot be satisfactorily compared. Finally, a retention indicator is used in modelling estimates for vertical transmission of HIV. Without accurate and correct estimates, it is not possible to evaluate programme achievements effectively in respect of elimination of mother-to-child transmission of HIV. This consideration may become particularly important as recent programmatic data seem to indicate a stagnation in the achievements of PMTCT programmes worldwide, which suggests the need for revised global, national, and local strategies to end the HIV epidemic by 2030. (26).

\section{List Of Abbreviations}

\begin{tabular}{ll}
\hline PMTCT & Prevention of mother-to-child transmission of HIV \\
\hline ART & Antiretroviral treatment \\
\hline WHO & World Health Organisation \\
\hline IATT & Inter-Agency Task Team \\
\hline HEI & HIV-exposed infants \\
\hline ePLD & Electronic patient-level database \\
\hline PEPFAR & United States President's Emergency Plan for AIDS Relief \\
\hline MCH & Mother and child health \\
\hline VL & Viral load \\
\hline MOH & Ministry of Health \\
\hline IQR & Interquartile range \\
\hline
\end{tabular}

\section{Declarations}


Ethics approval and consent to participate: This study was part of the 'Identifying Optimal Models of HIV Care and Treatment' collaboration which was approved by the Mozambican National Ethics Committee and the Columbia University Medical Center IRB. Additional technical and administrative approval was received from the US Centers for Disease Control and Prevention and the Office of the Global AIDS Coordinator, US Department of State. Informed consent to participate was not required as this study was solely based on secondary data analyses of de-identified routine service delivery data. As part of the 'Optimal Models' Collaboration, the Columbia University IRB Committee did not consider this study to be a human subject research, as there was no interaction with subjects and no intervention, and private, identifiable information was not collected.

Consent for publication: All authors have provided consent for the publication of this manuscript.

Availability of data and material: No original data were used in the study; only secondary routinely collected de-identified service delivery data were used. The datasets analysed during the current study are currently not publicly available. An anonymised dataset can be available from the corresponding author on reasonable request.

Competing interests: The authors declare that they have no competing interests.

Funding: No source of funding was used for this study.

Authors' contributions: LA, TT, SA, RB, ML participated in the study design. LA carried out the data collection and LA, TT, SA participated in the data analysis. LA drafted the manuscript, TT, SA, ML, DA and FD participated in the revision of the drafted manuscript and all authors read and approved the final manuscript.

\section{Acknowledgements:}

The authors thank all women and infants who used the PMTCT services in Nampula and Zambézia provinces. We would like to recognise the hard work and valuable contributions of the health facility and health information system staff at the health facilities and at ICAP in Mozambique.

We would also like to thank Elaine Abrams for her comments and support on this work. The corresponding author thanks the Bordeaux Population Health Research Center for covering the article processing charge and the Elsevier Editing Support group for English language editing of the manuscript.

\section{References}

1. World Health Organization. Guideline on when to start antiretroviral therapy and on pre-exposure prophylaxis for HIV (2015). Available at http://www.who.int/hiv/pub/guidelines/earlyrelease-arv/en/ (accessed 24 Nov2017).

2. World Health Organization Programmatic Update: Use of antiretroviral drugs for treating pregnant women and preventing HIV infection in infants. Executive Summary. April 2012. Available at 
https://www.who.int/hiv/pub/mtct/programmatic_update2012/en/ (accessed on 23 Nov 2017).

3. World Health Organization. Guideline on when to start antiretroviral therapy and on pre-exposure prophylaxis for HIV (2015). Available at http://www.who.int/hiv/pub/guidelines/earlyrelease-arv/en/ (accessed 24 Nov2017).

4. Phiri S, Tweya H, van Lettow M, Rosenberg NE, Trapence C, Kapito-Tembo A, et al. Impact of facilityand community-based peer support models on maternal uptake and retention in Malawi's Option B+ HIV Prevention of Mother-to-Child Transmission Program: a 3-arm cluster randomized controlled trial (PURE Malawi). J Acquir Immune Defic Syndr. 2017;75 Suppl 2:S140-8.

5. Tiffany G. Harris. HIV-positivity among HIV-exposed infants in Lesotho in the era of Option B+. Poster \# 823 presented at: Conference on Retroviruses and Opportunistic Infections (CROI, 2018); 2018 Mar 4; Boston, USA.

6. Hosseinipour M, Nelson JAE, Trapence C, Rutstein SE, Kasende F, Kayoyo V, et al. Viral suppression and HIV drug resistance at 6 months among women in Malawi's Option B+ program: results from the PURE Malawi study. J Acquir Immune Defic Syndr. 2017;75 Suppl 2:S149-55.

7. Nsubuga-Nyombi T, Sensalire S, Karamagi E, Aloyo J, Byabagambi J, Rahimzai M, et al. Multivariate analysis of covariates of adherence among HIV-positive mothers with low viral suppression. AIDS Res Ther. 2018;15:9.

8. Kiyaga C, Narayan V, McConnell I, Elyanu P, Kisaakye LN, Kekitiinwa A, et al. Retention outcomes and drivers of loss among HIV-exposed and infected infants in Uganda: a retrospective cohort study. BMC Infect Dis. 2018;18:416.

9. Mulu A, Maier M, Liebert UG. Upward trends of acquired drug resistances in Ethiopian HIV-1C isolates: A decade longitudinal study. PloS One. 2017;12:e0186619.

10. TenoRes Study Group. Global epidemiology of drug resistance after failure of WHO recommended first-line regimens for adult HIV-1 infection: a multicentre retrospective cohort study. Lancet Infect Dis. 2016;16:565-75.

11. Boender TS, Kityo CM, Boerma RS, Hamers RL, Ondoa P, Wellington M, et al. Accumulation of HIV-1 drug resistance after continued virological failure on first-line ART in adults and children in subSaharan Africa. J Antimicrob Chemother. 2016;71:2918-27.

12. 90-90-90 - An ambitious treatment target to help end the AIDS epidemic. Available at http://www.unaids.org/en/resources/documents/2017/90-90-90 (accessed on 23 Nov 2017).

13. World Health Organization. Retention in HIV programmes: defining the challenges and identifying solutions. Meeting report; 13-15 September 2011, Geneva, Switzerland. Available at https://www.who.int/hiv/pub/meetingreports/retention_programmes/en/ (accessed on 23 Nov 2017).

14. Mugavero MJ, Davila JA, Nevin CR, Giordano TP. From access to engagement: measuring retention in outpatient HIV clinical care. AIDS Patient Care STDs. 2010;24:607-13.

15. Rollins NC, Becquet R, Orne-Gliemann J, Phiri S, Hayashi C, Baller A, et al. Defining and analyzing retention-in-care among pregnant and breastfeeding HIV-infected women: unpacking the data to 
interpret and improve PMTCT outcomes. J Acquir Immune Defic Syndr. 2014;67:S150-56.

16. World Health Organization, Department of HIV/AIDS. Consolidated strategic information guidelines for HIV in the health sector: HIV strategic information for impact. 2015. http://www.ncbi.nlm.nih.gov/books/NBK299486/. Accessed on 7 Nov 2018.

17. Inter-Agency Task Teams (IAAT), Kampala, Uganda. B+ Monitoring \& evaluation framework dissemination and country consultation adapting monitoring \& evaluation systems for cohort and enhanced monitoring as well as outcome and impact evaluations/assessments. Executive summary of technical findings. 2015. https://www.childrenandaids.org/sites/default/files/201704/IATT_B\%2BMonitoring-and-Evaluation-Framework_2016.pdf. Accessed on 7 Nov 2018.

18. Rollins NC, Essajee SM, Bellare N, et al. Improving retention in care among pregnant women and mothers living with HIV: lessons from INSPIRE and implications for future WHO guidance and monitoring. J Acquir Immune Defic Syndr 2017;75(Suppl 2):S111-4.

19. Ministério da Saúde (MISAU), Serviço Nacional de Saúde, República de Moçambique. Tratamento antiretroviral e infeções oportunistas do adulto, adolescente, Grávida e Criança Guião de Bolso. http://www.misau.gov.mz/index.php/guioes. Accessed on 10 Oct 2018.

20. Ahoua L, Tiendrebeogo T, Arikawa S, Lahuerta M, Aly D, Journot V, Abrams EJ, Becquet R, Dabis F. PMTCT care cascade and factors associated with attrition in the first four years after Option B+ implementation in Mozambique. Trop Med Int Health TMIH 2019; doi: 10.1111/tmi.13324. [Epub ahead of print].

21. República de Moçambique Ministério da Saúde Direção Nacional de Assistência Medica. Plano nacional de monitoria e avaliação de HIV/SIDA: 2013-2017. Maputo, Mozambique: MISAU; 2012.

22. Joseph J, Gotora T, Erlwanger AS, Mushavi A, Zizhou S, Masuka N, et al. Impact of point-of-care CD4 testing on retention in care among HIV-positive pregnant and breastfeeding women in the context of Option B+ in Zimbabwe: a cluster randomized controlled trial. J Acquir Immune Defic Syndr. 2017;75 Suppl 2:S190-7.

23. Jiamsakul A, Kerr SJ, Kiertiburanakul S, Azwa I, Zhang F, Chaiwarith R, et al. Early suboptimal ART adherence was associated with missed clinical visits in HIV-infected patients in Asia. AIDS Care. 2018;30:1560-6.

24. Crawford TN, Thornton A. Retention in continuous care and sustained viral suppression. J Int Assoc Provid AIDS Care. 2017;16:42-7.

25. Mutasa-Apollo T, Ford N, Wiens M, Socias ME, Negussie E, Wu P, et al. Effect of frequency of clinic visits and medication pick-up on antiretroviral treatment outcomes: a systematic literature review and meta-analysis. J Int AIDS Soc. 2017;20(Suppl 4):21647.

26. UNAIDS. Fast track: Ending the AIDS epidemic by 2030.

https://www.unaids.org/sites/default/files/media_asset/fast-track-commitments_en.pdf. Accessed on 1 Dec 2018.

\section{Tables}


Table 1: Retention definitions and methods of calculation. B+ PMTCT programme, Mozambique, 20132017

\begin{tabular}{|c|c|c|}
\hline $\begin{array}{l}\text { Type of } \\
\text { retention }\end{array}$ & $\begin{array}{l}\text { Definition of a patient 'alive and retained in care' at } 12 \text { months post- } \\
\text { ART initiation }\end{array}$ & Failure event \\
\hline $\begin{array}{l}\text { 'Point' } \\
\text { retention }\end{array}$ & $\begin{array}{l}\text { Alive and had a visit at the health facility } 12 \text { months post-ART } \\
\text { initiation or if was known to have had a visit at a health facility } \\
\text { any time after }\end{array}$ & $\begin{array}{l}\text { Death, LTFU, and transfer-out are counted if } \\
\text { they occurred within the first } 12 \text { months } \\
\text { post-ART initiation }\end{array}$ \\
\hline WHO & $\begin{array}{l}\text { Attendance at a health facility at } 12 \text { months post-ART initiation*, } \\
\text { or at any time up to } 3 \text { months later }\end{array}$ & $\begin{array}{l}\text { Death, LTFU, and transfer-out are counted if } \\
\text { they occurred within the first } 15 \text { months } \\
\text { post-ART initiation. } \\
\text { Patients transferred out were right-censored } \\
\text { at the date of transfer-out }\end{array}$ \\
\hline $\mathrm{MOH}$ & Attendance at a health facility at 12 months post-ART initiation* & $\begin{array}{l}\text { Death or LTFU are counted if either occurred } \\
\text { within the first } 12 \text { months post-ART } \\
\text { initiation } \\
\text { Patients transferred out are excluded from } \\
\text { the analysis }\end{array}$ \\
\hline IATT & $\begin{array}{l}\text { Attendance at a health facility and on treatment at } 1,2,3,6,9 \text {, and } \\
12 \text { months post-ART initiation \# }\end{array}$ & $\begin{array}{l}\text { Death, LTFU, transfers-out and failure to } \\
\text { attend either the } 1-, 2-, 3-, 6-, 9-\text {, or } 12 \text {-month } \\
\text { visit, whichever comes first } \\
\text { Patients are right-censored at the date of } \\
\text { the } 1^{\text {st }} \text { failure event. }\end{array}$ \\
\hline $\begin{array}{l}\text { 'Appointment } \\
\text { adherence' } \\
\text { retention }\end{array}$ & $\begin{array}{l}\text { Attendance at a health facility at } 12 \text {-months post-ART initiation * } \\
\text { and } 075 \% \text { of appointment adherence to scheduled visits } \\
\text { 'Appointment adherence' was estimated using the number of visits } \\
\text { attended divided by the number of total scheduled visits during } \\
\text { the } 12 \text {-month observation period }\end{array}$ & Not applicable \\
\hline $\begin{array}{l}\text { 'On-time } \\
\text { adherence' } \\
\text { retention }\end{array}$ & $\begin{array}{l}\text { Attendance at a health facility at } 12 \text { months post-ART initiation * } \\
\text { and } 775 \% \text { of 'on-time attendance to scheduled visits } \\
\text { A visit on time is defined as a visit that occurred within }+/-15 \text { days } \\
\text { of the date of the expected scheduled visit } \\
\text { 'On-time adherence' is estimated using the number of visits } \\
\text { attended on-time divided by the number of total scheduled visits. } \\
\text { Unscheduled visits occurring before the date of appointment were } \\
\text { not counted as missed visits }\end{array}$ & $\begin{array}{l}\text { Death, LTFU, transfer-out, and failure to } \\
\text { attend a visit on-time, whichever comes } \\
\text { first. } \\
\text { Patients were right-censored at the date of } \\
\text { the } 1^{\text {st }} \text { failure event }\end{array}$ \\
\hline
\end{tabular}

ART, antiretroviral therapy; LTFU, lost to follow-up

*For these definitions, we considered a window period of +/- 15 days around the theoretical date of 12-month post-ART initiation.

\# We allowed a +/-15-day window period for each stage of ART follow-up. Note: We did not consider 'appointment adherence' retention for the survival analysis, as this definition does not contemplate a time event but rather the total number of visits completed during the observation period. 
Table 2: Sensitivity and specificity of various definitions of retention in care among B+ HIV+ pregnant women defined as alive and retained in care according to the 'point' retention definition $(n=16,840)$.

\begin{tabular}{|c|c|c|c|c|c|}
\hline \multirow[t]{2}{*}{$\begin{array}{l}\text { Retained in care according to } \\
\text { type of definition } \\
(n=16,840)\end{array}$} & \multicolumn{2}{|c|}{$\begin{array}{l}\text { Alive and retained in care with } \square 75 \% \\
\text { of visits in time } \\
\text { (Reference) }\end{array}$} & \multirow[t]{2}{*}{$\begin{array}{l}\text { Sensitivity } \\
95 \% \mathrm{Cl}\end{array}$} & \multirow[t]{2}{*}{$\begin{array}{c}\text { Specificity } \\
95 \% \mathrm{Cl}\end{array}$} & \multirow[t]{2}{*}{$\begin{array}{c}\% \text { of } \\
\text { misclassification }\end{array}$} \\
\hline & Yes & No & & & \\
\hline 'Point' retention & 407 & 16,433 & - & - & $97.6 \%$ \\
\hline WHO & 405 & 13,154 & $\begin{array}{r}3.0 \%[2.7 \%- \\
3.3 \%]\end{array}$ & $\begin{array}{r}99.9 \%[99.8 \%- \\
100 \%]\end{array}$ & $78.1 \%$ \\
\hline $\mathrm{MOH}$ & 407 & 9,093 & $\begin{array}{r}4.3 \%[3.9 \%- \\
4.7 \%]\end{array}$ & $\begin{array}{r}100 \%[99.9 \%- \\
100 \%]\end{array}$ & $54.0 \%$ \\
\hline IATT & 249 & 2,515 & $\begin{array}{r}9.0 \%[8.0 \%- \\
10.1 \%]\end{array}$ & $\begin{array}{r}98.9 \%[98.7 \%- \\
99.0 \%]\end{array}$ & $15.9 \%$ \\
\hline $\begin{array}{l}\text { 'Appointment adherence' } \\
\text { retention }\end{array}$ & 407 & 3,076 & $\begin{array}{r}11.7 \%[10.6 \%- \\
12.8 \%]\end{array}$ & $\begin{array}{r}100 \%[100 \%- \\
100 \%]\end{array}$ & $18.3 \%$ \\
\hline
\end{tabular}

Note: The 'on-time adherence' definition of retention is considered as the reference $(n=407$ women retained in care at 12 -months post-ART initiation and with $575 \%$ on-time adherence to scheduled visits). The percentage of misclassified patients is calculated using the sum of patients incorrectly classified according to each definition divided by the total number of patients included in the analysis.

Table 3: Advantages, limitations, and programmatic practicality of six measures of retention in care for PMTCT option B+ programmes. 


\begin{tabular}{|c|c|c|c|}
\hline $\begin{array}{l}\text { Retention } \\
\text { definition }\end{array}$ & Advantages & Limitations & Programmatic practicality \\
\hline $\begin{array}{l}\text { 'Point' } \\
\text { retention }\end{array}$ & $\begin{array}{l}\text { Easy to measure } \\
\text { Assessed at a single time point } \\
\text { Provide a transversal picture of } \\
\text { retention }\end{array}$ & $\begin{array}{l}\text { Does not consider visit consistency } \\
\text { of the MIP } \\
\text { Does not consider whether the } \\
\text { women fully adhered to the } 12- \\
\text { month visit schedule } \\
\text { Not aligned with important PMTCT } \\
\text { milestones (i.e. delivery, EID, or final } \\
\text { HIV testing) }\end{array}$ & $\begin{array}{l}\text { Programmatic definition of } \\
\text { retention } \\
\text { Achievable with simple } \\
\text { health information systems } \\
\text { (e.g. paper-based registers) }\end{array}$ \\
\hline WHO & $\begin{array}{l}\text { Easy to measure } \\
\text { Assessed at a single time point } \\
\text { Provide a transversal picture of } \\
\text { retention } \\
\text { More specific in detecting patients } \\
\text { adhering to the } 12 \text {-month visit (up } \\
\text { to } 15 \text {-months only) }\end{array}$ & $\begin{array}{l}\text { Does not consider visit consistency } \\
\text { of the MIP } \\
\text { Not aligned with important PMTCT } \\
\text { milestones (i.e. delivery, EID, or the } \\
\text { end of breastfeeding) }\end{array}$ & As above \\
\hline $\mathrm{MOH}$ & $\begin{array}{l}\text { Easy to measure } \\
\text { Assessed at a single time point } \\
\text { Provides a transversal picture of } \\
\text { retention } \\
\text { Considers whether the women fully } \\
\text { adhered to the } 12 \text {-month visit } \\
\text { schedule }\end{array}$ & As above & $\begin{array}{l}\text { Programmatic definition of } \\
\text { retention } \\
\text { Achievable with simple } \\
\text { health information systems } \\
\text { (e.g. paper-based registers) } \\
\text { Cohort based approach for } \\
\text { calculation }\end{array}$ \\
\hline IATT & $\begin{array}{l}\text { Considers whether the women fully } \\
\text { adhered to the } 12 \text {-month visit } \\
\text { schedule } \\
\text { Captures visit consistency } \\
\text { Can be adapted to align with the } \\
\text { follow-up of the MIP }\end{array}$ & $\begin{array}{l}\text { More complex to measure (ideally } \\
\text { requires an ePLD or POC EMR) } \\
\text { Not systematically aligned with } \\
\text { national PMTCT follow-up } \\
\text { guidelines but can be modified } \\
\text { accordingly } \\
\text { Probable need of data } \\
\text { triangulation with other data } \\
\text { sources (e.g. pharmacy, } \\
\text { laboratory) and linkage with } \\
\text { unique IDN }\end{array}$ & $\begin{array}{l}\text { Relevant in capturing visit } \\
\text { consistency of the MIP, can } \\
\text { be aligned with important } \\
\text { PMTCT milestones } \\
\text { Ideal if integrated POC } \\
\text { testing services for the MIP } \\
\text { are available } \\
\text { Better alternative than single } \\
\text { time point estimations }\end{array}$ \\
\hline $\begin{array}{l}\text { 'Appointment } \\
\text { adherence' } \\
\text { retention }\end{array}$ & $\begin{array}{l}\text { Considers whether the women truly } \\
\text { adhered to the 12-month visit } \\
\text { schedule } \\
\text { Capture visit consistency } \\
\text { Measurable with paper-based } \\
\text { longitudinal cohort based registers } \\
\text { (total \# of completed visits } \\
\text { done/total scheduled visits) }\end{array}$ & $\begin{array}{l}\text { Does not capture the regularity or } \\
\text { timeliness of completed visits } \\
\text { Not aligned with important PMTCT } \\
\text { milestones for the MIP } \\
\text { Highly dependent on data } \\
\text { completeness of denominator (\# } \\
\text { of scheduled visits) } \\
\text { Need of data triangulation with } \\
\text { other data sources (e.g. pharmacy, } \\
\text { laboratory) and linkage with } \\
\text { unique IDN }\end{array}$ & $\begin{array}{l}\text { Achievable with simple } \\
\text { health information systems } \\
\text { Better alternative than single } \\
\text { time point estimations }\end{array}$ \\
\hline
\end{tabular}




\begin{tabular}{|c|c|c|c|}
\hline $\begin{array}{l}\text { Retention } \\
\text { definition }\end{array}$ & Advantages & Limitations & Programmatic practicality \\
\hline $\begin{array}{l}\text { 'On-time } \\
\text { adherence' } \\
\text { retention }\end{array}$ & $\begin{array}{l}\text { Considers whether the women fully } \\
\text { adhered to the } 12 \text {-month visit } \\
\text { schedule } \\
\text { Ideal to capture correct levels of } \\
\text { engagement in care for PMTCT } \\
\text { (regularity and timeliness) } \\
\text { Aligned with important milestones } \\
\text { of PMTCT follow-up for the MIP }\end{array}$ & $\begin{array}{l}\text { More complex to measure } \\
\text { (requires an ePLD or POC EMR) } \\
\text { Highly dependent on data } \\
\text { completeness of denominator (\# } \\
\text { of scheduled visits) } \\
\text { Need of data triangulation with } \\
\text { other data sources (e.g. pharmacy, } \\
\text { laboratory) and linkage with } \\
\text { unique IDN } \\
\text { Time consuming activity not } \\
\text { compatible with one-stop model } \\
\text { PMTCT services in the absence of } \\
\text { electronic databases }\end{array}$ & $\begin{array}{l}\text { Adapted for research } \\
\text { purposes } \\
\text { Not compatible with routine } \\
\text { monitoring of retention in } \\
\text { care of MIPs }\end{array}$ \\
\hline
\end{tabular}

Note: EID, early infant diagnosis; EMR, electronic medical record; ePLD, electronic patient-level database; IDN, identification number; MIP, mother-infant pair; POC, point-of-care

\section{Figures}

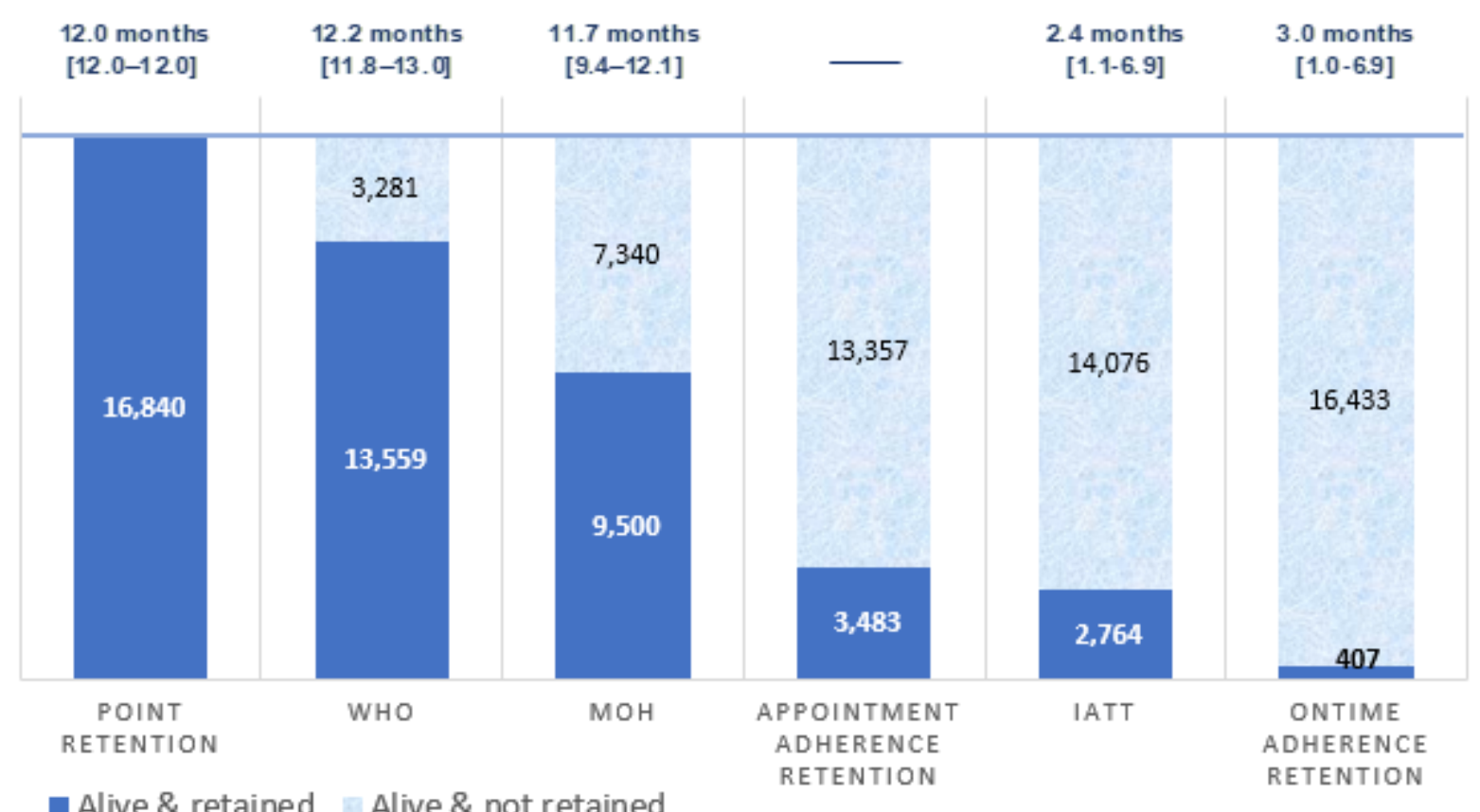

* Note: Time until first failure event expressed in months, median, and interquartile range

\section{Figure 1}

B+ pregnant women retained in care 12 months post-ART initiation: time to first failure event. 

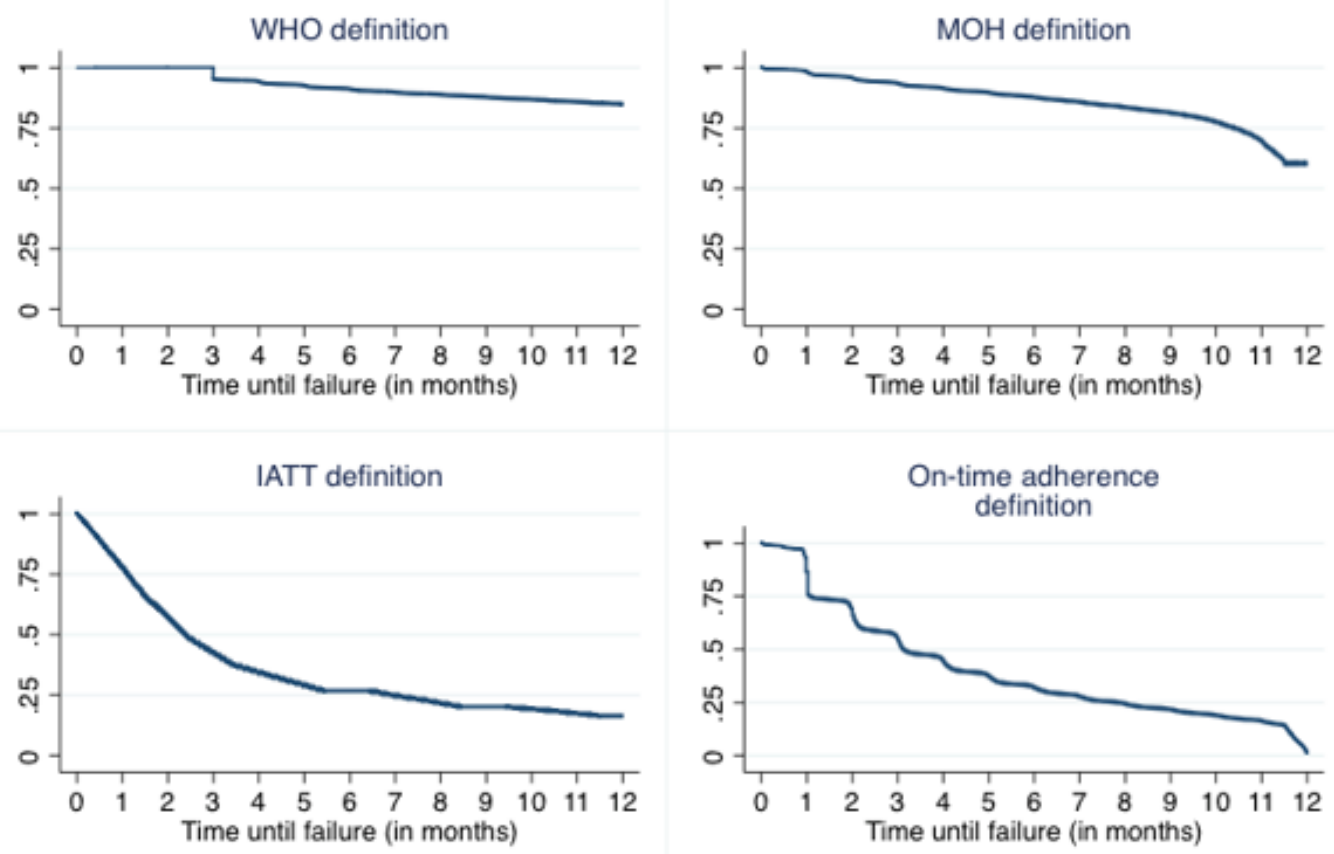

$95 \% \mathrm{Cl}$

Survivor function

\begin{tabular}{|c|c|c|c|c|c|}
\hline Time to failure event & 0 months & 3 months & 6 months & 9 months & 12 months \\
\hline \multicolumn{6}{|l|}{ WHO definition } \\
\hline$\#$ at risk & 16,840 & 16,838 & 15,359 & 14,793 & 11,448 \\
\hline$\#$ events & - & 797 & 703 & 559 & 493 \\
\hline \# events (cumulative) & - & 797 & 1,500 & 2059 & 2,552 \\
\hline Retention (95\% CI) & - & $95.3 \%(94.9-95.6)$ & $91.1 \%(90.7-91.5)$ & $87.8 \%(87.3-88.3)$ & $84.8 \%(84.2-85.3)$ \\
\hline \multicolumn{6}{|l|}{ MOH definition } \\
\hline$\#$ at risk & 15,750 & 14,743 & 13,834 & 12,829 & 6,099 \\
\hline$\#$ events & - & 759 & 902 & 1,011 & 3,302 \\
\hline \# events (cumulative) & - & 759 & 1,661 & 2672 & 5974 \\
\hline Retention $(95 \% \mathrm{CI})$ & - & $93.4 \%(93.0-93.8)$ & $87.7 \%(87.2-88.2)$ & $81.3 \%(80.7-81.9)$ & $60.3 \%(59.6-61.1)$ \\
\hline \multicolumn{6}{|l|}{ IATT definition } \\
\hline$\#$ at risk & 16,840 & 7,163 & 4,514 & 3,402 & 1,855 \\
\hline$\#$ events & - & 5,937 & 2,649 & 1,112 & 637 \\
\hline \# events (cumulative) & - & 5,937 & 8,586 & 9,698 & 10,335 \\
\hline Retention $(95 \% \mathrm{CI})$ & - & $42.5 \%(41.8-43.3)$ & $26.8 \%(26.1-27.5)$ & $20.2 \%(19.6-20.8)$ & $16.4 \%(15.8-17.0)$ \\
\hline \multicolumn{6}{|l|}{ On-time definition } \\
\hline$\#$ at risk & 15,232 & 8,508 & 4,907 & 3,265 & 154 \\
\hline \# events & - & 4,838 & 3,420 & 1,551 & 2,979 \\
\hline \# events (cumulative) & - & 4,838 & 8,258 & 9,809 & 12,788 \\
\hline Retention $(95 \% \mathrm{CI})$ & - & $54.8 \%(53.9-55.6)$ & $32.2 \%(31.4-32.9)$ & $21.8 \%(21.2-22.5)$ & $1.2 \%(1.0-1.4)$ \\
\hline
\end{tabular}

Note: Kaplan-Meier survival curves for retention over time are presented by retention definition for B+ HIV-positive pregnant women up to 12 months post-ART initiation.

\section{Figure 2}

Estimated Kaplan-Meier survival curves for retention over time, by retention definition. 